\title{
Synthesis of Silica Hybrid Nanoparticles and the Effect of Their Addition on the Hardness of the Dental Nanocomposites
}

\author{
Roziamarni Che Abdul Aziz, Ismail Ab Rahman, Dasmawati Mohamad \\ School of Dental Sciences, Universiti Sains Malaysia 16150 Kubang Kerian, Kelantan, Malaysia \\ E-mail: marni2312@yahoo.com,arismail@usm.my,dasmawati@kck.usm.my
}

\begin{abstract}
The objective of this study is to investigate the effect of silica hybrid nanoparticles on the hardness of the dental nanocomposites. The silica hybrid nanoparticles were synthesized by sol-gel method. The powders were modified with 3methacryloxy-propyltrimethoxy silane ( $\gamma$-MPS) either by co-condensation method or one-pot method. The silanized silica were then mixed with a mixture of bisglycidyl methacrylate (BisGMA), triethylene glycol methacrylate (TEGDMA), camphorquinone (CQ) and dimethylaminoethyl methacrylate (DMAEMA) to form dental nanocomposites. The hardness of the nanocomposites were determined using vickers hardness. The results shown that hardness of the dental composites using silica hybrid nanoparticles synthesized via one-pot method was higher compared to the synthesized via co-condensation method. Transmission Electron Microscope (TEM), and Fourier Transform Infrared Spectroscopy (FTIR) were used for characterization.
\end{abstract}

Keywords - sol-gel; modified nanosilica; dental nanocomposites; hardness

\section{INTRODUCTION}

Recently, hybrid composites for tooth restoration have been widely used instead of amalgam. The composites have good aesthetics and make up for the weak points of amalgam such as toxicity from mercury content, corrosion and low adhesive property.

The inorganic filler such as silica has been used as filler in fabrication of hybrid dental composite to improve shrinkage and enhance the strength. Sol-gel process is a common method for silica synthesis. The process involves simultaneous hydrolysis and polycondensation reaction of silicon alkoxide. Different morphology of silica can be produced by sol-gel process by careful controlling parameters such as $\mathrm{pH}$, water ratio and alkoxide ratio. The general reaction lead to the formation of silica particles can be written as [1]:

$$
\begin{aligned}
& \mathrm{Si}(\mathrm{OR})_{4}+\mathrm{H}_{2} \mathrm{O} \rightarrow \mathrm{Si}(\mathrm{OR})_{3} \mathrm{OH}+\mathrm{ROH} \\
& \mathrm{Si}(\mathrm{OR})_{4}+\mathrm{Si}(\mathrm{OR})_{3} \mathrm{OH} \rightarrow \\
& (\mathrm{RO})_{3} \mathrm{Si}-\mathrm{O}-\mathrm{Si}(\mathrm{OR})_{3}+\mathrm{ROH}
\end{aligned}
$$

$\equiv \mathrm{Si}-\mathrm{OH}+\mathrm{HO}-\mathrm{Si} \equiv \rightarrow \equiv \mathrm{Si}-\mathrm{O}-\mathrm{Si} \equiv+\mathrm{H}_{2} \mathrm{O}$
For synthesizing hybrid composite, modification of silica surface with silane coupling agent will enhance compatibility of filler with polymeric matrix due to their unique bifunctional structure with one end capable of reacting with the silanol groups of silica surface and the other end compatible with the polymer. This will increase the hardness and strength of the dental composites [2].

Most of the literature used post-modification method (grafting) for modification of silica $[3,4]$. However, the postmodification is time and energy consuming and the use of organic solvent. Another method, co-condensation method is also used. This technique can produce a more homogeneous incorporation of inorganic functional group to the interior and exterior of the bulk of silica particle [5].

This work focused on the synthesis of silica nanoparticles with size ranging from 10-100 nm by sol-gel method by carefully controlled the amount of ammonia as catalyst (or $\mathrm{pH})$. Their surfaces were modified with 3-(trimethoxysilyl) propyl methacrylate $(\gamma$-MPS), coupling agents, via a new technique known as one pot, and compared to the cocondensation method. The effect of addition of unmodified and modified silica hybrid nanoparticles on the hardness of the dental hybrid nanocomposites was investigated. 


\section{MATERIAL AND METHOD}

\section{A. Reagents}

Tetraethoxysilane (TEOS,99\%, Fluka), absolute ethanol (EtOH, 99.8\%, Systerm), 3-(trimethoxysilyl)propyl methacrylate ( $\gamma$-MPS, $98 \%$, Aldrich) ammonia $\left(\mathrm{NH}_{3}, 25 \%\right.$, Merck), BisGMA, TEGMA, camphorquinon (CQ, 97\%, Aldrich), dimethylaminoethyl methacrylate (DMAEMA, Merck).

\section{B. Standard Procedure}

A quantity of $7.76 \mathrm{~mL}$ of TEOS were dissolved in 38.8 $\mathrm{mL}$ of ethanol under low frequency ultrasound (Branson, Model $3510,42 \mathrm{kHz}$ ) at room temperature for 10 minutes. Then, $0.846 \mathrm{~mL}$ of distilled water with feed rate $0.2 \mathrm{~mL} / \mathrm{min}$ were dropped into the mixture. After 2 hours, $2.5 \mathrm{~mL}$ of ammonia (Method 1) were dropped into the reaction mixture with feed rate $0.1 \mathrm{~mL} / \mathrm{min}$. Three different sizes of silica nanoparticles were produced by three different amount of ammonia. For Method 2 and 3,5mL and $10 \mathrm{~mL}$ ammonia were dropped. The gelled samples were washed with ethanol and distilled water (three times) and were centrifuged (4000 $\mathrm{rpm}, 7 \mathrm{~min}$ ) to remove the unreacted and excess catalyst. The samples were dried under vacuum for overnight in a freeze dryer (Thermo ModulyoD). Finally, the samples were calcined at $600^{\circ} \mathrm{C}$ for $2 \mathrm{~h}$.

\section{Modification of nanosilica via co-condensation and one- pot method}

Silica nanoparticles were prepared under same conditions as standard procedure but in co-condensation method, a quantity of $2 \mathrm{~mL}$ of $\gamma$-MPS as coupling agent were added together with TEOS and ethanol. In one-pot method, $\gamma$-MPS were added at the end of the synthesis procedure. Then, the samples were calcined at $110^{\circ} \mathrm{C}$ for $2 \mathrm{~h}$. Experimental conditions for the preparation of silica nanoparticles were tabulated in Table 1 .

TABLE I

COMPOSITION FOR THE PREPARATION OF MODIFIED SILICA NANOPARTICLES

\begin{tabular}{|c|c|c|c|}
\hline Reagent/molL $^{-1}$ & Method 1 & Method 2 & Method 3 \\
\hline$[\mathrm{TEOS}]$ & 0.64 & 0.64 & 0.64 \\
\hline $\begin{array}{c}{\left[\mathrm{H}_{2} \mathrm{O}\right] /} \\
{[\mathrm{TEOS}]+[\gamma-\mathrm{MPS}]}\end{array}$ & 0.1 & 0.1 & 0.1 \\
\hline$[\mathrm{NH} 3]$ & 0.6 & 1.2 & 2.4 \\
\hline
\end{tabular}

\section{E. Characterizations of silica nanoparticles}

Transmission electron microscopy (TEM) images were taken using a Philips CM 12. FTIR spectra were recorded using a Perkin Elmer Spectrum 100. The diameters of 100 particles were measured for the average particles size and the standard deviation using AnalySis 2.11 image analyzer software.

\section{F. Preparation of dental hybrid nanocomposites}

The Bis-GMA as a base monomer was mixed with TEGMA (50:50 wt/wt). Then, the photoinitiator system CQ and DMAEMA (1\%wt) were added to the mixture. Then, three sizes of filler, silica were mixed with the resin by hand spatulation. Finally, the paste of dental nanocomposites were molded and light cured for hardness testing using vickers hardness VM50.

\section{RESULT AND DISCUSSION}

\section{A. Characterization of silica nanoparticles}

Figure 1 shows the TEM images of silica nanoparticles prepared by using three different amount of ammonia before and after modification via co-condensation and one-pot method. The morphology of the particles were spherical nanosize with low aggregation. Figure 2 shows particle size distribution of the unmodified and modified silica. The average particle size for unmodified silica were $19.6 \pm 3.3$ $\mathrm{nm}, 27.6 \pm 2.3 \mathrm{~nm}$ and $64.6 \pm 8.2 \mathrm{~nm}$ for $0.6 \mathrm{molL}^{-1}, 1.2$ $\mathrm{molL}^{-1}$ and $2.4 \mathrm{molL}^{-1}$ concentration of ammonia, respectively. For modified silica via co-condensation method, the average particle size were $18.6 \pm 5.6 \mathrm{~nm}, 31.8 \pm 4.6 \mathrm{~nm}$ and $68.0 \pm 6.5 \mathrm{~nm}$. The average particle size for modified silica via one-pot method were $25.16 \pm 6.1 \mathrm{~nm}, 32.09 \pm 5.6$ $\mathrm{nm}$ and $62.13 \pm 8.0 \mathrm{~nm}$ (Table 2). The results agreed with those reported by Kim et al. [6], the particles size increased by increasing amounts of the catalysts (ammonia). The ammonia increased the rate of hydrolysis and also condensation reaction, which induces the growth of the particles. After modification, there were slightly increased particle sizes but not on particle distribution.

TABLE II

EFFECT OF ADDITION OF AMMONIA, MODIFICATION VIA CO-CONDENSATION AND ONE POT ON PARTICLE SIZE OF NONOSILICA

\begin{tabular}{|c|c|c|c|}
\hline \multirow{2}{*}{$\begin{array}{c}\text { Ammonia } \\
\text { (molL }^{-1} \text { ) }\end{array}$} & \multicolumn{3}{|c|}{ Average particle size (nm) } \\
\cline { 2 - 4 } & $\begin{array}{c}\text { Unmodified } \\
\text { SiO }_{\mathbf{2}}\end{array}$ & $\begin{array}{c}\text { SiO }_{2} \text {-MPS co- } \\
\text { condensation }\end{array}$ & $\begin{array}{c}\text { SiO2-MPS } \\
\text { one-pot }\end{array}$ \\
\hline 0.6 & $19.6 \pm 3.3$ & $18.6 \pm 5.6$ & $25.16 \pm 6.1$ \\
\hline 1.2 & $27.6 \pm 2.3$ & $31.8 \pm 4.7$ & $32.09 \pm 5.6$ \\
\hline 2.4 & $64.6 \pm 8.2$ & $68.0 \pm 6.5$ & $62.13 \pm 8.0$ \\
\hline
\end{tabular}

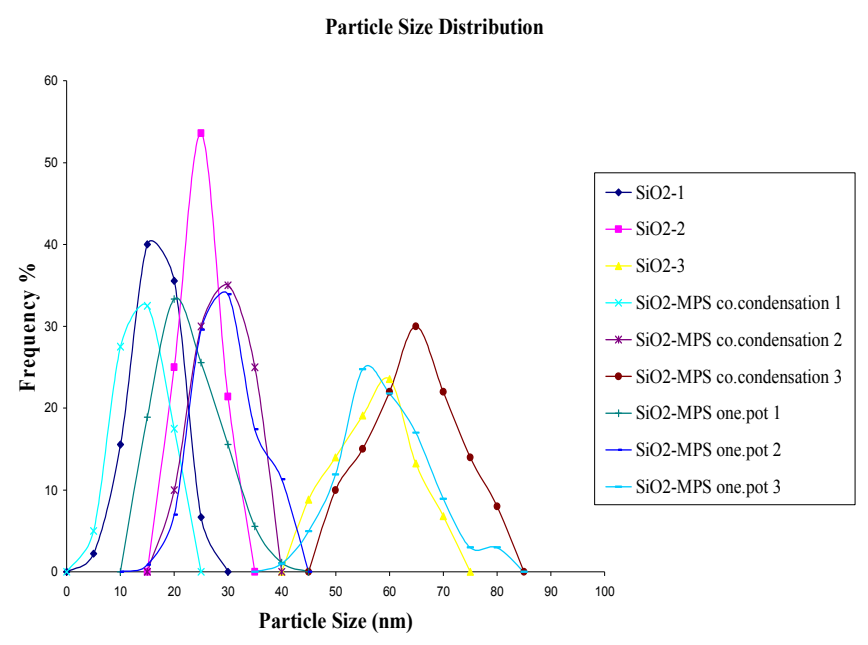

Fig.2 Particle size distribution of nanosilica with different amount of ammonia, after co-condensation and one pot modification. 

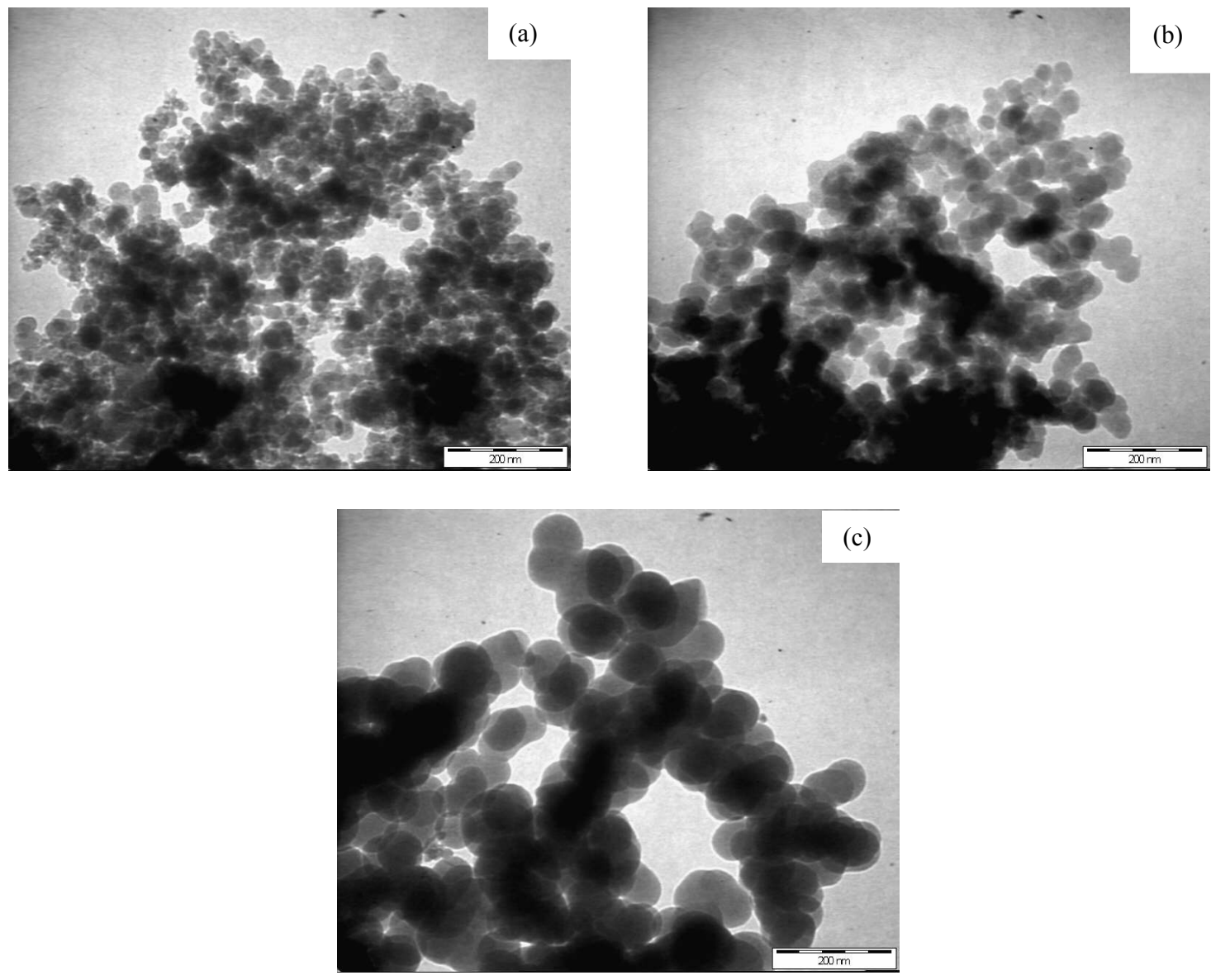

Fig. 1 TEM of unmodified silica nanoparticles in different amount of ammonia (a) $0.6 \mathrm{molL}^{-1}$ (b) $1.2 \mathrm{molL}^{-1}$ (c) $2.4 \mathrm{molL}^{-1}$

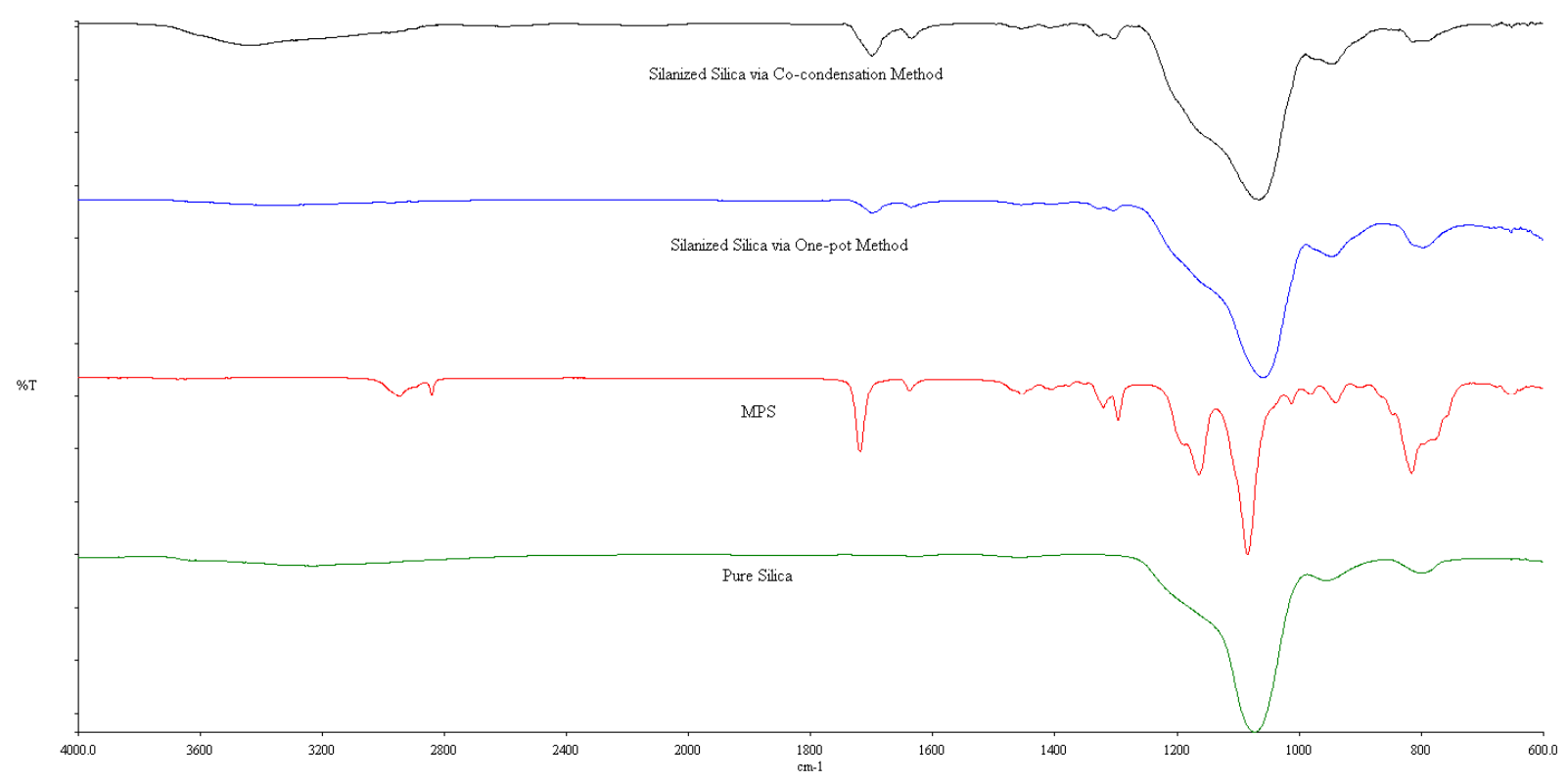

Fig.3 FTIR spectra of pure silica, $\gamma$-MPS and modified silica 
Figure 3 shows the functional group in the modified silica nanoparticles compared to the pure silica and $\gamma$-MPS using FTIR. The spectra show that the bands at 1720, 1700, 1635, 1320 and $1300 \mathrm{~cm}^{-1}$ were indicating the presence of $\gamma$-MPS on the surface of the silica. The bands at $1720 \mathrm{~cm}^{-1}$ is due to the free carbonyl $(\mathrm{C}=\mathrm{O})$ and the peak at $1700 \mathrm{~cm}^{-1}$ is carbonyl groups which from hydrogen bonds with the silica or adjacent silane hydroxyls. The absorption bands at 1630 and $1320 \mathrm{~cm}^{-1}$ are due to the stretching vibration of the $\mathrm{C}=\mathrm{C}$ bond in MPS and $\mathrm{Si}-\mathrm{CH}_{2}$, respectively. The bands at 1062 and $940 \mathrm{~cm}^{-1}$ correspond to the asymmetric stretching and bending of silanols groups $(\mathrm{Si}-\mathrm{OH})$ on the silica surface. Intensive bands at $1200-1100 \mathrm{~cm}^{-1}$ represent the asymmetric stretching and bending of siloxane groups ( $\mathrm{Si}-\mathrm{O}-\mathrm{Si})[7,8]$.

\section{B. Hardness of the dental nanocomposites.}

Table 3 shows that the filler loads of dental nanocomposites were increased with addition of coupling agent, $\gamma$-MPS. The filler load for unmodified silica maximum at $\sim 50 \%$ compared to the modified silica, which can go up to $\sim 60 \%$. From the results show that the hardness value of dental nanocomposites were increased by increasing the filler load. The hardness value of dental nanocomposite for modified silica via one-pot method were slightly increased compared with modified silica via co-condensation method. This due to the homogeneous distribution of the filler in one-pot method.

TABLE III

HARDNESS VALUE OF DENTAL NANOCOMPOSITES USING UNMODIFIED AND MODIFIED NANOSILICA

\begin{tabular}{|c|c|c|}
\hline $\begin{array}{c}\text { Dental hybrid nanocomposites } \\
\text { Type of Silica }\end{array}$ & $\begin{array}{c}\text { \% Filler } \\
\text { Loading }\end{array}$ & $\begin{array}{c}\text { HV1kgf } \\
\text { (mean } \pm \text { SD) }\end{array}$ \\
\hline Unmodified Silica & $40 \%$ & $24.7 \pm 2.6$ \\
\hline \multirow{2}{*}{$\begin{array}{c}\text { Modified silica via } \\
\text { co-condensation method }\end{array}$} & $40 \%$ & $17.7 \pm 4.7$ \\
\cline { 2 - 3 } & $50 \%$ & $34.7 \pm 10.4$ \\
\cline { 2 - 3 } & $60 \%$ & $36.5 \pm 7.5$ \\
\hline \multirow{2}{*}{$\begin{array}{c}\text { Modified silica via } \\
\text { one-pot method }\end{array}$} & $40 \%$ & $24.5 \pm 2.6$ \\
\cline { 2 - 3 } & $50 \%$ & $39.6 \pm 10.7$ \\
\cline { 2 - 3 } & $60 \%$ & $42.4 \pm 9.3$ \\
\hline
\end{tabular}

\section{CONCLUSIONS}

A stable modified nanosilica has been synthesized by using a co-condensation and one-pot method. Ammonia influences the particle size of the nanosilica. With increasing the concentration of ammonia, the particle size of the silica was increased. The hardness values of modified nanosilica were increased compared to the modified nanosilica.

\section{ACKNOWLEDGMENT}

The authors appreciate Universiti Sains Malaysia for financial support of this research under Incentive Grant (Grant No. 1001/PPSG/8122018). Roziamarni would like to express her gratitude to USM for Fellowship.

\section{REFERENCES}

[1] K. S. Rao, K. El-Hami, T. Kodaki, K. Matsushige and K. Makino, "A novel method for synthesis of silica nanoparticles," Journal of Colloid and Interface Science, vol. 289, pp. 125-131, May 2005.

[2] A. Karmaker, A. Prasad and N. K. Sarkar, "Characterization of adsorbed silane on fillers used in dental composite restoratives and its effect on composite properties," J Mater Sci: Mater Med, vol. 18, pp. 1157-1162, Feb. 2007.

[3] K. C. Vrancken, K. Possemiers, P. Van Der Voort and E. F. Vansant, "Surface modification of silica gels with aminoorganosilanes," Colloids Surface A: Physicochem. Eng. Aspects, vol. 98, pp. 235-241, 1995.

[4] P. Vejayakumaran, I. A. Rahman, C. S. Sipaut, J. Ismail and C. K. Chee, "Structural and thermal characterizations of silica nanoparticles grafted with pendant maleimide and epoxide groups," Journal of Colloid and Interface Science, vol. 328, pp. 81-91, Sept. 2008 .

[5] H. Seong, W. W. Jerzy, Y. Ji-Chul, P. Marek and L. S. Y. Victor, "Organic functionalization and morphology control of mesoporous silicas via a co-condensation synthesis method," Chem. Mater., vol. 15, pp. 4247-4256, March 2003.

[6] J. W. Kim, L. U. Kim and C. K. Kim, "Size control of silica nanoparticles and their surface treatment for fabrication of dental nanocomposites," Biomacromolecules, vol. 8, pp. 215-222, Dec. 2006.

[7] I. D. Sideridou and M. M. Karabela, "Effect of the structure of silane-coupling agent on dynamic mechanical properties of dental resin-nanocomposites," Journal of Applied Polymer Science, vol. 110, pp. 507-516, July 2008.

[8] W. Posthumus, P. C. M. M. Magusin, J. C. M. Brokken-Zijp, A. H. A. Tinnemans and R. Van der Linde, "Surface modification of oxidic nanoparticles using 3-methacryloxypropyltrimethoxysilane," Journal of Colloid and Interface Science, vol. 269, pp. 109-116, 2004.

[9] M. Jafarzadeh, I. A. Rahman and C. S. Sipaut, "Optical properties of amorphous organo-modified silica nanoparticles produced via cocondensation method," Ceramics International, vol. 36, pp. 333-338, Sept. 2009.

[10] M. Dui and Y. Zheng, "Modification of silica nanoparticles and their application in UDMA dental polymeric composites," Polymer Composites, pp. 198-207, 2007. 